\title{
A REVIEW ON LEAN MANUFACTURING METHOD IMPLEMENTATION IN MANUFACTURING INDUSTRY
}

\section{SASANKA CHAUDHRY \& DHIRENDRANATH THATOI}

\author{
Department of Management, Siksha 'O' Anusandhan (Deemed To Be University), Bhubaneswar, Odisha
}

\begin{abstract}
Lean production is an established path to fabrication industry growth. However, most companies struggled to adopt lean production program in their attempts. The move to lean output involves fundamental transformation requiring a total reshaping of the organization's mission, structure and community. This paper provides an investigation into the impact of systemic reform on the lean industrial process. Lean manufacturing reflects a systematic solution to transition. A major systemic transition will arise within the company, in order to build the basis for lean manufacturing to take place. This research used an informative mixed system methodology, which started with the dissemination of surveys, and then the general image was further improved by performing in-depth interviews on automotive firms.The findings showed that an organization that stressed leadership and management, improving agent structure, efficient collaboration, and encouragement of the worker by preparation and team growth, as well as lean review program encountered a seamless shift to lean production framework. Failure to recognize the systemic changes required to adopt the lean fabrication method would delay the organization's long-term benefits.

KEYWORDS: Automotive Firms, Implementation of Lean Manufacturing, Lean Manufacturing, Organization Development
\end{abstract}

Received: Jun 08, 2020; Accepted: Jun 28, 2020; Published: Aug 27, 2020; Paper Id.: IJMPERDJUN2020912

\section{INTODUCTION}

Change is not an anomaly today but a constant phase moving forward. Since transition has its own effect on systems as well as on individuals, focus is also needed. Managing organizational transition is an activity that guarantees that the specific aspects comply with corporate policy, technologies, and business processes. Researchers described organizational transition as the mechanism by which organizations, in order to improve their efficiency, shift from their present state to a desired state. Whereas, they pointed out that organizational change is the change in authority, expertise, knowledge, or communication distribution with changes in ability distribution and capacity requirement[1].

If a business wants to transform into a lean organization, it is proposed that the business often has to adjust the way they view the various aspects of the job. Moving to lean production method is a revolutionary operation, and not a simple job. Lean manufacturing reflects a systematic solution to transition[2]. A major systemic transition will arise within the company, in order to build the basis for lean manufacturing to take place. According to experts, the lean transformation phase involves major improvements in the company's functions. They stated that lean transformation involves new strategy in the study of managing the shift to a lean enterprise.The new approach happens as the organisation's environment is understood and legitimized[3]. 
Changes in lean manufacturing that need can be separated into four groups as proposed by the researchers. Table 1 demonstrates the improvements that are expected during the lean fabrication process. Lean production requires organizational transition and quality enhancement. For performance, the shift from lean manufacturing is prerequisite. Engagement in leadership and management is the most important success drivers in lean production led by connectivity, team growth, organizational preparation and flexibility of workers[4].If the connection between organizational changes is not well understood, transition to lean manufacturing method will fail. To be successful in today's global industrial climate, businesses need to establish a method of systemic transition and prepare to embrace the introduction of lean manufacturing[5].

Table 1: Organisational Changes Required in Lean Manufacturing Implementation

\begin{tabular}{|l|l|}
\hline \multicolumn{1}{|c|}{ Categories in organisational change } & \multicolumn{1}{c|}{ Changes in lean manufacturing } \\
\hline Changes in power within the organisation & Decentralised responsibilities, autonomous leadership. \\
\hline Changes in walues and human behawiour & $\begin{array}{l}\text { Teamwork open communication and information } \\
\text { sharing, continuous improvement culture, knowledge } \\
\text { learning and sharing. }\end{array}$ \\
\hline Changes in function, coordination and control & $\begin{array}{l}\text { Teanwork buiding, cross-functional movement, } \\
\text { network relationship with suppliers and customers, } \\
\text { information transparency, participative management, } \\
\text { teamwork rewarding. }\end{array}$ \\
\hline Changes in process & $\begin{array}{l}\text { Application of the full set of lean tools, multi-skilled } \\
\text { worker. }\end{array}$ \\
\hline
\end{tabular}

So far, there is little discussion about the connection between handling organizational change and introducing lean manufacturing. Indeed, one of the key tasks in lean implementation is to steer the path in transformation as outlined in the implementation document. That's because lean manufacturing needs systemic, program, method, and employee behaviour changes. This notion points to the need for further work in order to efficiently adopt lean production cycle where the operational transition is handled effectively[6].Therefore, there is need to consider the essence of organizational transition in lean manufacturing and the elements required to achieve effective lean adoption in a manufacturing business. The aim of this paper is to examine the effect of organizational reform on the effective adoption of lean production method. Failure to consider the systemic improvements needed to adopt the lean development system would impede the organization's longterm benefits[7].

\section{RESEARCH METHODOLOGY}

An analytical hybrid process framework was used for this research, where the organizational improvement drivers in the adoption of lean manufacturing were first explored by quantitative process, and then further clarified by qualitative methodology. The quantitative and qualitative data were gathered sequentially in this method, where the first step was the distribution of surveys and then accompanied by in-depth interviews to further clarify or expand on the quantitative findings.

Survey: A questionnaire has been created for data collection at this stage. The various automobile manufacturing firms were chosen as target community to achieve the study's objectives. Delivery industries inventory covers electrical, mechanical, metal, plastic, rubber and other vehicle parts. The industrial businesses included in this analysis varied from small to major enterprises, with over 50 workers. Medium-sized companies are those with full-time workers from 51-150 
according to SME Corp, while big businesses are companies with more than 151 full-time employees.From their research, small production firms are seen to be less inclined to adopt LM principles because of such constraints and obstacles. Survey employees included those from managing partners, sales and/or development managers and administrators, as well as consistency management and supervisors[8].

The questionnaire consisted of four parts: (a) corporate context details (year of incorporation, ownership, number of workers, and quality control certification); (b) lean manufacturing adoption (lean application of practices); (d) operational transition factors; and (d) respondent details (job description, position and years of employment). The products in the Implementation portion of lean production have been adapted from analysis. In addition to concerns on lean practice region, seven issues were introduced on the understanding of attempts to reform organisation[9].For this survey tool, the primary concern of the questionnaire design was to keep it brief and centered so that a sufficient answer rate was reached. In the case of the durability test, Cronbach's alpha was used to assess the testing instrument's internal accuracy. All the findings have shown that the survey instrument has a good internal accuracy with Cronbach's 0.60 alpha values and is thus accurate.

For an in-depth interview three automotive manufacturing firms were chosen. Such businesses were chosen on the grounds of their ability to engage and their expertise in lean programs. The researchers planned the set of data by first approaching each organization to be analysed, outlining the intent of the report, and documenting key contact details. A semi-structured interview guide was built based on a popular case study methodology based on literature analysis and precase research quantitative survey. The interview procedure was developed to explore lean obstacles in automotive industries that hindered the lean adoption phase.

To boost the precision of the study, multiple interviewees were using the same interview procedure for triangulation purposes. The requirement for triangulation stems from the ethical imperative of verifying the authenticity of the collected results. The topics of the interview are being asked about their real experiences. For each respondent the interviews were performed for around two hours. They also included main business staff who are actively interested with introducing lean production.The initial questionnaire was sent out via emails to 140 target respondents. Nonetheless, they received a total of 18 answers. In addition, this provided a very low response rate of $12.6 \%$. The researchers were dissatisfied with the initial answer rate and are searching for other ways to submit a questionnaire through postal mail. As a result, the number of replies increased to 50 and the response rate thus strengthened to $30 \%$. Cluster research was conducted to distinguish the businesses into lean, non-lean and in-transition lean organizations and describe the lean position of each of the respondent businesses concerned.Cluster represents a category that is measured as the total values of the vector lean activities for all organizations which shows the degree of the group's lean fabrication implementation. Depending on the hierarchical cluster classification of their mean scores for each person lean process, organizations were categorized as lean, in-transition or lean utilizing the Euclidian squared gap between variables and Ward's method of maximizing the total variation across clusters. Table 2 displays the mean scores for the solutions for the three clusters[10].

The first category (A) had 14 firms as a consequence of the cluster study, which was distinguished by low mean values for all five variables in lean practices. This indicates that limited lean production strategies were adopted by the companies comprising this cluster and classified as non-lean businesses. The second category (B) had 30 firms for each of the five factors, which was distinguished by modest mean values. This category is known as in-transition companies to 
lean fabrication method. Ultimately, the third category (C), which had 17 companies, is known as lean companies as it is distinguished by large mean values of variables in each lean manufacturing activities.

A standard lean implementation requires the initial value stream mapping (VSM) that determines the change pathway. That is the house's organizing. These may involve adaptive job processes and (particularly) 5S (sorting, sustaining, standardizing, straightening, and systematic cleaning). Many similar methods are then applied as appropriate. Those comprise daily job, single minute dies exchange (SMED), complete productivity management (TPM), and Jidoka error proofing. Other developments may involve supply and demand, including just-in-time (JIT) pull systems and Heijunka (level scheduling).

Table 2: Mean values for three cluster analysis solutions for lean practices

\begin{tabular}{|l|l|c|c|c|c|}
\hline & $\begin{array}{l}\text { Non- } \\
\text { lean } \\
\text { (A) }\end{array}$ & In-transition(B) & $\begin{array}{l}\text { L ean } \\
\text { (C) }\end{array}$ & \multicolumn{2}{|c|}{ ANOVA } \\
\cline { 2 - 6 } & $\mathrm{n}=14$ & $\mathrm{n}=30$ & $\mathrm{n}=16$ & $\mathrm{~F}$ & $\mathrm{p}-$ walue \\
\hline Customer relationship & 2.74 & 3.47 & 4.35 & 36.51 & .00 \\
\hline Supplier relationship & 2.47 & 3.25 & 4.05 & 57.54 & .00 \\
\hline Human resources & 3.10 & 3.50 & 4.39 & 36.80 & .00 \\
\hline $\begin{array}{l}\text { Manufacturing process } \\
\text { and control }\end{array}$ & 2.90 & 3.54 & 4.44 & 47.08 & .00 \\
\hline Process and equipment & 2.81 & 3.50 & 4.27 & 57.36 & .00 \\
\hline
\end{tabular}

The findings in Table 2 also demonstrate that ANOVA is one-way independent to decide whether the gap between non-lean (A), in-transition (B) and lean (C) cluster means is important. The aim of this test is to evaluate the predictive viability and accuracy of the cluster across groups with predicted rates of experience. To test for variance homogeneity, the Levene method was used for variance consistency. The Levene test found that all lean methods are not important ( $p>0.05$ ) except for Procedure and facilities, which suggested that the variances of population are fairly similar for each category. The F-ratio is used to check if the group mean is the same.A major systemic transition will arise within the company, in order to build the basis for lean production to take place. Correlation test was conducted to ensure the association between drivers of organizational transition and lean implementation status persists. Nevertheless, in this analysis the data challenged parametric expectations for organizational transition variables such as non-normally distributed results. Therefore, non-parametric equations using the tau coefficient of Kendall. 
Table 3: Kendall's tau correlation coefficient and Kruskal-Wallis test results of organisational change variables and lean implementation status

\begin{tabular}{|c|c|c|c|}
\hline \multirow{2}{*}{ Organisational change factors } & \multirow{2}{*}{$\begin{array}{c}\begin{array}{c}\text { Kendal's } \\
\text { tau }\end{array} \\
\text { (r) }\end{array}$} & \multicolumn{2}{|c|}{ Kruskal-Wallis } \\
\hline & & df & Result \\
\hline Change readiness: the management & $0.394^{* 6}$ & .010 & Sig \\
\hline Change readiness: the employees & $0.335 * 0$ & .002 & Sig \\
\hline Production team & $0.464^{* \bullet}$ & .001 & Sig \\
\hline Leadership and management support: the top management & $0.301^{* \bullet}$ & .017 & Sig \\
\hline Leadership and management support: the middle management & $0.422 * 0$ & .004 & Sig \\
\hline Effective communication & $0.441^{\circ 6}$ & .000 & Sig \\
\hline Employee training & $0.384^{\circ *}$ & .007 & Sig \\
\hline Change agent system & $0.354^{* 0}$ & .029 & Sig \\
\hline Reward system & 0.109 & .219 & Not sig. \\
\hline Review process & 0.211 & .044 & Sig \\
\hline
\end{tabular}

Table 3 points out the associations to lean deployment status for each of the organizational improvement variables. The findings indicate a strong positive association with lean status, since most are significant at $\mathrm{p}<.01$ except for the Evaluation Method, which is significant at $\mathrm{p}<.05$. However, it has not been seen that Incentive Scheme has any major connection to lean implementation status. It is also proved that, except for the incentive scheme, higher lean adoption rank may be correlated with higher organizational improvement factors.

Later, to further explore the interaction between organizational change factors in lean adoption, a study was performed to look into the discrepancies between organizational change factors in three lean status classes. As the data compromise the strict expectations of a one-way ANOVA, it was agreed that a Kruskal-Wallis check would be carried out. The findings of the Kruskal-Wallis check to evaluate the means of organizational improvement factors between non-lean, in-transition and lean companies are also seen in Table 3. Table 3 results show that all indicators of behavioural transition were greatly influenced by lean status classes with $\mathrm{p}<.05$ except for "Reward System." This result suggests that, in various forms of lean status classes, there are variations in the above described organizational reform initiative.

Researchers are searching for approaches in the sense of organizational reform that can promote efficiency, that is, to achieve sustainable benefits. Lean development policy is usually a senior management judgment, that is to say a topdown transition plan. Although the change management cycle has several examples, the mechanism isn't often as effective as planned. As the management of transition demonstrates, sudden transitions create opposition. Lean is a philosophy at the deepest stage, that is, a collection of corporate behaviours, rather than simply utilizing resources. The survival depends on the community of organisation and the mutual reaction to the transition.

The survival depends on the community of organisation and the mutual reaction to the transition. In addition, many of the lean methods are advanced in their necessity for a specific culture group, providing clear intrinsic encouragement for the processes at the shop floor level (e.g., kaizen, 5S, six sigmas, consistency rings, and job cages). Implementing lean therefore includes a change management mechanism that fosters results, thereby improving leadership by coaching as opposed to pure top-down reform directives. The concept of consideration for humanity is as essential in a lean environment as the reduction of waste.

Lean is generally identified with the above and part reverence for humans is mostly overlooked. True lean means reflecting on an organization's staff, building a mind-set that empowers workers at all levels to make creative improvements that boost profitability while growing inefficient (muda) behaviour. Which produces new transition 
management agencies, which are diverse and scalable. Efficient and efficient dialog mechanisms provide for cooperation and agreement, as well as mutual purpose and dedication.

\section{CONCLUSION}

Basically, the key aim of this paper is to explain how drivers of internal transformation support industrial organizations move to a lean production framework. From the findings and outcomes of this report, it seems that for a smooth transition to lean manufacturing framework, certain aspects need to be stressed. Good leadership and management, competent change agent program, efficient collaboration, workplace satisfaction by preparation and team growth, as well as robust lean evaluation framework are the organizational improvement components the organisation has emphasised.

Moving to lean manufacturing method is not a simple process. Because lean adoption is a systematic endeavour, it is important to consider the concerns regarding organizational reform related to lean development. Such research is of special interest not just because it is about lean manufacturing, but also because it should be conducted by other industrial firms in the future in a sense of the change of lean manufacturing. This research is intended to provide clinicians a clearer overview of the lean process and unambiguous advice to mitigate the uncertainty and disputes in lean manufacturing method implementation.

\section{REFERENCES}

1. J. Bhamu and K. S. Sangwan, "Lean manufacturing: Literature review and research issues," International Journal of Operations and Production Management. 2014.

2. S. M. Zahraee, "A survey on lean manufacturing implementation in a selected manufacturing industry in Iran," Int. J. Lean Six Sigma, 2016.

3. A. Susilawati, J. Tan, D. Bell, and M. Sarwar, "Fuzzy logic based method to measure degree of lean activity in manufacturing industry," J. Manuf. Syst., 2015.

4. M. Begam, R. Swamynathan, and J. Sikkizhar, "Current Trends on Lean Management-A review," Int. J. Lean Think., 2013.

5. R. Davies, T. Coole, and A. Smith, "Review of Socio-technical Considerations to Ensure Successful Implementation of Industry 4.0," Procedia Manuf., 2017.

6. N. S. Gandhi, S. J. Thanki, and J. J. Thakkar, "Ranking of drivers for integrated lean-green manufacturing for Indian manufacturing SMEs, "J. Clean. Prod., 2018.

7. S. Gupta, M. Sharma, and V. Sunder M, "Lean services: a systematic review," International Journal of Productivity and Performance Management. 2016.

8. N. Kumar, S. Kumar, A. Haleem, and P. Gahlot, "Implementing lean manufacturing system: ISM approach," J. Ind. Eng. Manag., 2013.

9. S. Prasad, D. Khanduja, and S. K. Sharma, "An empirical study on applicability of lean and green practices in the foundry industry,” J. Manuf. Technol. Manag., 2016.

10. N. Nordin, B. Md. Deros, D. A. Wahab, and M. N. Mohd, "Managing change in lean manufacturing implementation," in Advanced Materials Research, 2011. 